\title{
Uit de knoop
}

Rationeel-emotieve therapie en andere cognitieve gedragstherapiën bij kinderen en adolescenten 


\section{Uit de knoop}

Rationeel-emotieve therapie en andere cognitieve gedragstherapieën bij kinderen en adolescenten

Gidia Jacobs

Nicole Muller

Esther ten Brink

Bohn Stafleu Van Loghum

Houten/Diegem 2001 
Alle rechten voorbehouden. Niets uit deze uitgave mag worden verveelvoudigd, opgeslagen in een geautomatiseerd gegevensbestand, of openbaar gemaakt, in enige vorm of op enige wijze, hetzij elektronisch, mechanisch, door fotokopieën, opnamen, of enig andere manier, zonder voorafgaande schriftelijke toestemming van de uitgever.

Voorzover het maken van kopieën uit deze uitgave is toegestaan op grond van artikel 16b Auteurswet $1912 \mathrm{j}^{\mathrm{o}}$ het Besluit van 20 juni 1974, Stb. 351, zoals gewijzigd bij Besluit van 23 augustus 1985, Stb. 471 en artikel 17 Auteurswet 1912, dient men de daarvoor wettelijk verschuldigde vergoedingen te voldoen aan de Stichting Reprorecht (Postbus 882, 1180 AW Amstelveen). Voor het overnemen van (een) gedeelte(n) uit deze uitgave in bloemlezingen, readers en andere compilatiewerken (artikel 16 Auteurswet 1912) dient men zich tot de uitgever te wenden.

Samensteller(s) en uitgever zijn zich volledig bewust van hun taak een zo betrouwbaar mogelijke uitgave te verzorgen. Niettemin kunnen zij geen aansprakelijkheid aanvaarden voor onjuistheden die eventueel in deze uitgave voorkomen.

ISBN 9031336971

NUGI 713

$\mathrm{D} / 2001 / 3407 / 149$

Ontwerp omslag: totdrukwerk

Tekening omslag: Frank van Tussenbroek

Bohn Stafleu Van Loghum

Het Spoor 2

3994 AK Houten

Motstraat 30

2800 Mechelen

www.bsl.nl 


\section{Inhoud}

Ter introductie 11

Woord vooraf 13

\section{Deel 1 Inleiding, methoden, relatie 15}

1 Inleiding 17

1.1 Geschiedenis 17

1.2 Theorie 18

1.2.1 Een holistische benadering 18

1.2.2 Modellen 20

1.3 Praktische en emotionele problemen 25

1.4 Hier-en-nu-aanpak 25

1.5 Specifieke aspecten van de praktijk 26

1.5.1 Algemeen 27

1.5.2 Ontwikkelingstheoretische kaders 28

1.6 Toepassingsmogelijkheden 29

1.6.1 Indicaties 29

1.6.2 Leeftijd 30

1.6.3 Wie wordt behandeld? 31

1.7 Langetermijneffecten 33

2 Cognitief-gedragstherapeutische methoden 35

2.1 Inleiding 35

2.2 Cognitieve therapie en rationeel-emotieve therapie 36

2.3 Zelfcontroletraining 38

2.4 Zelfinstructietraining 40

2.5 Interpersoonlijke probleemoplossingsvaardighedentraining 41

2.6 Stressinoculatietraining 43

2.7 Attributiehertraining 44

2.8 Hoe te kiezen? 46

3 Het fundament van de relatie: bouwstenen en toepassingen 47

3.1 Inleiding 47

3.2 Bouwstenen 48

3.2.1 De therapeut als coach 48

3.2.2 Het kind als aanspreekpunt 49

3.2.3 Niets menselijks is vreemd 51

3.2.4 Betrokkenheid en confrontatie 53

3.2.5 Ik stuur, maar jij bent de baas 55

3.2.6 Uitgaan van de kracht van een kind 57 


\subsection{Jonge kinderen 58 \\ 3.4 Adolescenten 59 \\ 3.5 Vertrouwelijkheid 59}

\section{Deel 2 Diagnostiek met behulp van het ABC-model 61}

4 De start: een goed begin is het halve werk 63

4.1 Inleiding 63

4.2 Omgevingsfactoren 63

4.3 Verwachtingen 64

4.4 Grenzen 66

4.5 Motivatieproblemen 68

4.6 Introductie van het ABC-schema 71

4.7 Diagnostische middelen 71

4.7.1 De aard van de klacht 72

4.7.2 Manipulatief of non-manipulatief 74

4.7.3 Internaliseren of externaliseren 75

4.7.4 Het belang van de DSM-classificatie 77

4.7.5 Wie heeft de klacht? 79

4.8 Valkuilen 81

4.8.1 Op zoek naar verklaringen 81

4.8.2 Meegaan met de irrationaliteit van het cliëntsysteem 82

4.8.3 Er is thuis vast iets mis 82

4.8.4 Er moet iets Ernstigs zijn 83

4.8.5 Overige irrationele opvattingen van de therapeut 84

5 Formulering van de gebeurtenis en onderzoek van de gevoelens 85

5.1 Inleiding 85

5.2 Formulering van de gebeurtenis 85

5.3 Onderzoek van gevoelens 88

5.3.1 Gevoelens herkennen en benoemen 88

5.3.2 Intensiteit en inadequaatheid van gevoelens 95

5.3.3 Frequentie en duur van gevoelens 97

5.3.4 Relatie tussen gebeurtenis en gevoel 98

6 Onderzoek van gedrag en de gevolgen van gedrag 101

6.1 Inleiding 101

6.2 Op zoek naar verschillende gedragspatronen 102

6.3 Consequenties van gedrag 105

6.4 Hoe beoordelen kind en ouders het gedrag ? 107

7 Onderzoek van gedachten 111

7.1 Inleiding 111

7.2 Waarneming 112

7.3 Gevolgtrekkingen: interpretaties, attributies, veronderstellingen 114

7.4 Evaluaties 119

7.5 Kerncognities 121 
7.6 Cognities identificeren met behulp van verhalen en tekeningen en dergelijke 124

7.7 Slotopmerkingen over de diagnostiek 127

7.7.1 En dat allemaal in één sessie? 127

7.7.2 Openheid voor interventies 127

7.7.3 Een probleem over een probleem 128

7.7.4 Wat kan een goede start belemmeren? 129

\section{Deel 3 Interventies 131}

8 Cognitieve interventies 133

8.1 Inleiding 133

8.2 Een doel stellen 134

8.3 Opbouw van de sessies 139

8.4 De B-C-connectie 140

8.5 De aanpak van waarnemingsfouten 143

8.6 Het bewerken van verkeerde gevolgtrekkingen 146

8.7 Het bewerken van irreële evaluaties 152

8.8 Het bewerken van kerncognities 157

8.8.1 Ont-moeten 158

8.8.2 Het uitdagen van (zelf)veroordelingen 163

8.9 Alternatieve gedachten en positieve zelfspraak 166

9 Gevoelsinterventies 169

9.1 Inleiding 169

9.2 Voorwaarden voor succesvolle interventies 170

9.3 Emotieve educatie 170

9.4 Waarnemen en signaleren 175

9.5 Gevoelens langer ervaren 180

9.5.1 Negatieve gevoelens verdragen 180

9.5.2 Positieve gevoelens aanspreken 182

9.6 Gevoelens korter ervaren 185

9.6.1 Negatieve gevoelens korter ervaren 185

9.6.2 Positieve gevoelens korter ervaren 186

9.7 Gevoelens anders ervaren 187

9.8 Tot slot 189

10 Gedragsinterventies 191

10.1 Inleiding 191

10.2 Gedragseducatie 192

10.3 Geen woorden maar daden 194

10.4 Registratieopdrachten 196

10.5 Aansluiten bij adequaat gedrag 197

10.6 Schaamte- en risico-oefeningen 198

10.7 Belonen en straffen 201

10.8 Oefenen aan de hand van de therapeut 204 
10.9 Huiswerk 204

10.9.1 Inleiding 204

10.9.2 Bespreken aan het einde van de sessie 205

$10.10 \quad$ Tot slot 212

\section{Deel 4 Systeem, protocol, casus 213}

11 Systeemgerichte aanpak 215

11.1 Inleiding 215

11.2 Diagnostiek 217

11.2.1 Driehoeksverhoudingen 217

11.2.2 Uitvragen van cognities 219

11.2.3 Opvoedingsstijlen en -cognities 224

11.3 Motiveren voor behandeling 225

11.3.1 Oudertyperingen 225

11.3.2 Motivatie aanspreken 228

11.4 Behandeling 231

11.4.1 Doelen stellen 231

11.4.2 Gemeenschappelijke en individuele irrationele opvattingen aankaarten en uitdagen 233

11.4.3 Gedrags- en gevoelsveranderingen bewerkstelligen 237

11.5 Wanneer zie je wie? 240

11.6 Gesprek met de ouders van Demba 242

12 Protocollair werken 245

12.1 Inleiding 245

12.2 Coping Cat, een protocol voor de behandeling van angstige kinderen 246

12.2.1 Inleiding 246

12.2.2 Uitgangspunten 246

12.2.3 Inhoud 247

12.2.4 Een casus 247

12.3 Protocol voor depressieve jongeren: de depressiegroep 249

12.3.1 Inleiding 249

12.3.2 Uitgangspunten 250

12.3.3 Inhoud 250

12.3.4 Een zitting 251

12.4 Protocol voor jongeren met boosheidsproblematiek: de 'Anger Control' groep 256

12.4.1 Inleiding 256

12.4.2 Uitgangspunten 256

12.4.3 Inhoud 257

12.4.4 Beschrijving 258 
12.5 Protocol voor een groepsbehandeling van kinderen met ADHD 261 12.5.1 Inleiding 261

12.5.2 Uitgangspunten 262

12.5.3 Inhoud 262

12.5.4 Een casus 264

13 Weergave van een schoolmotivatieprobleem 267

Bijlage 1 Marcels Machtige Monster 275

Bijlage 2 Ludwig leert glimmen 277

Bijlage 3 Fasha, Dasha en Sasha Eekhoorn 280

Bijlage 4 Literatuursuggesties en websites voor kinderen en jeugdigen 282

Literatuur 286

De auteurs 292 


\section{Ter introductie}

Meerdere malen heb ik het genoegen gehad in Nederland te kunnen werken, door het geven van workshops over Rational Emotive Behavior Therapy ${ }^{1}$ aan Nederlandse therapeuten. Mijn ervaringen waren buitengewoon positief. Ik maakte kennis met hartelijke, gastvrije mensen die zich heel open en ontvankelijk toonden voor de ideeën die ik wilde overbrengen. Ik werd in Nederland geïntroduceerd door Theo IJzermans, voor een gastdocentschap in het Nederlandse gezondheidszorgonderwijs. Later nodigde Gidia Jacobs mij uit om aan het Instituut voor Rationeel-Emotieve Training workshops te verzorgen voor therapeuten die kinderen, adolescenten en hun ouders behandelen. Het werken in Nederland gaf mij meer inzicht in verschillen en overeenkomsten tussen mijn land en andere landen, in allerlei kwesties. Ik raakte onder de indruk van de bewonderenswaardige manier waarop de Nederlandse therapeuten omgingen met de kinderen die zij behandelden en hoezeer zij bereid waren om te leren en samen te werken. Ik genoot in alle opzichten van het beroepsmatig bij hen betrokken zijn.

Ik zie het als een grote eer dat mijn goede vriendin en collega drs. Gidia Jacobs mij heeft gevraagd de inleiding voor dit boek te schrijven. Zowel in Nederland als in de Verenigde Staten is waardevolle literatuur over Rationeel-Emotieve Therapie en andere cognitieve therapieën speciaal voor kinderen en adolescenten schaars. Dit boek belooft een schat aan wetenswaardigheden te bieden aan ieder die kinderen en adolescenten behandelt.

Wie het leest zal constateren dat het een bijzonder veelomvattend boek is. Deel 1 biedt een uitgebreide uitleg van de verschillende cognitieve modellen en een nauwkeurige beschrijving van cognitief-gedragsmatige methoden. Er wordt ook veel aandacht aan besteed hoe belangrijk het is om een goede therapeutische relatie te ontwikkelen met de jongere; diverse praktische suggesties hoe dit te bereiken zijn niet vergeten.

Deel 2 handelt over assessment van problemen en geeft uitleg in het bijzonder van emoties, gedragingen en irrationele overtuigingen. De uitvoerige, gedetailleerde gevalsbeschrijvingen, verspreid over de hoofdstukken, vormen een sprekende illustratie van het proces en zullen de therapeut in de praktijk zeker een helpende hand bieden.

Alle behandelaars zijn benieuwd naar interventiemogelijkheden. Deze staan centraal in de rest van het boek. In deel 3 komen cognitieve, emotieve en gedragsmatige interventies aan bod die zijn afgestemd op het stadium van ontwikkeling waarin de jongere zich bevindt. De nadruk ligt op cognitieve interventies. Immers, veel behandelaars hebben wel een gedegen training in de gedragsmatige aspecten van het werken met jongeren en hun gezinnen achter de rug, maar hebben zich nog weinig beziggehouden met de cognitieve kanten.

1 In de Verenigde Staten is het gebruikelijk te spreken over Rational-Emotive Behavior Therapy, afgekort tot REBT. In Nederland is besloten om niet van REGT maar van RET te blijven spreken. 
Deel 4 geeft een beschrijving van de systeembenadering, met diverse dialogen die de toepassing van de daarbij genoemde begrippen laten zien. Er worden ook uiteenlopende protocollen beschreven: voor de behandeling van kinderen met angstproblemen, met ADHD, en ook voor een groepsbehandeling van depressieve kinderen en jongeren die leren hun woede te beheersen. Een bijna letterlijk weergegeven gevalsbeschrijving waarin de principes van het werken met jongeren tot uiting komen is hieraan toegevoegd.

Dit boek omvat de basis en veel meer dan dat van de Rationeel-Emotieve Therapie en andere cognitieve therapieën voor kinderen en adolescenten. De waardevolle informatie in ieder hoofdstuk biedt de lezer specifieke toepassingen en interventiemogelijkheden die een enorme uitbreiding van hun kennis en vaardigheid in het behandelen van jongeren zullen betekenen. Het lijdt geen twijfel: dit boek levert een onschatbare bijdrage aan de tot nu bestaande literatuur.

Ann Vernon, PhD

Professor and Coordinator of Counseling,

Department of Educational Administration and Counseling,

University of Northern Iowa, USA,

Director of the Midwest Center for REBT 


\section{Woord vooraf}

Dit boek is een praktische gids voor kindertherapeuten, psychologen, pedagogen, psychiaters en andere hulpverleners die in de GGZ werken met kinderen in de leeftijd van 7 tot en met 18 jaar.

Hoewel er de laatste jaren steeds meer boeken zijn verschenen over de cognitieve gedragsbenaderingen, is de literatuur wat kinderen betreft toch vooral beperkt gebleven tot het Engelstalige gebied. We hebben daarom een Nederlandstalig boek willen presenteren, dat tevens een surplus vormt bij reeds bestaand werk. Dit boek geeft vooral veel praktijkvoorbeelden, waarin de gespreksvoering zoals die met kinderen en adolescenten verloopt werkelijkheidsgetrouw voor het voetlicht gebracht worden. Het gevolg is dat de theorie voornamelijk aan de hand van voorbeelden getoond wordt.

We hebben getwijfeld of we er bij het schrijven van het boek van uit moesten gaan dat het boek voor beginnende kindertherapeuten bedoeld was of voor therapeuten die al jaren ervaring hadden in het werken met kinderen. We zijn er uiteindelijk in geslaagd om aan beide groepen tegemoet te komen. Het is mogelijk om dit boek te lezen zonder dat er sprake is van voorkennis van de rationeel-emotieve therapie (RET), maar we denken dat degenen die goed op de hoogte zijn van de basisprincipes meer profijt zullen hebben van dit boek. In het boek worden geregeld principes uit de RET gebruikt zoals 'tweede-niveauproblematiek' of 'egoangst en LFT' die voor therapie met volwassenen elders uitgebreid beschreven staan (Jacobs, 1998). Het is dan ook aan te bevelen om naar de genoemde verwijzing terug te grijpen wanneer bepaalde principes onvoldoende bekend voorkomen.

Het boek is tot stand gekomen naar aanleiding van een samenwerkingsverband tussen de auteurs. Toen we enkele jaren geleden voor het post-academisch onderwijs (PAO) een cursus Cognitieve gedragstherapie voor kinderen en jeugdigen gingen verzorgen, vonden we voldoende inspirerende artikelen om een reader voor de cursus samen te stellen, maar het materiaal was eenvoudigweg niet beschikbaar in de vorm die we het liefst zagen. De combinatie van onze drie werkvelden maakte dat er voldoende variatie kon ontstaan: Esther ten Brink werkt voornamelijk met jongere kinderen bij de RIAGG en is gespecialiseerd in ADHD; Nicole Muller heeft binnen de klinische jeugdpsychiatrie met jongeren en hun ouders gewerkt en is speciaal voor het tot stand komen van dit boek ook met jonge kinderen aan de slag gegaan; Gidia Jacobs werkt voornamelijk met de populatie pubers en ouders die men zoal in een eigen praktijk tegenkomt. Deze waaier aan ervaringen ontvouwt zich in de zeer diverse voorbeelden.

De RET vormt de basis voor het boek. Dit blijkt bijvoorbeeld uit de omvang van het hoofdstuk over cognitieve interventies. Cognities worden (of werden?) wel eens gelijk gesteld met bewuste, rationele en vooral verbale processen. De mythe dat daarin geen plaats is voor het ervaren van emoties omdat er vooral gesproken zou worden over emoties, is inmiddels wel ontzenuwd (zie ook Korrelboom, 
2000). Dit boek toont hoe emoties, gedrag en cognities als drie kanten van dezelfde medaille aangesproken worden in de therapie.

In dit boek gebruiken we de woorden therapeut en therapeute door elkaar. Er zijn meer vrouwelijke dan mannelijke therapeuten in de kinder-GGZ en daar de voorbeelden die we beschrijven allemaal uit onze eigen dagelijkse praktijk stammen, was het prettig om ook in de vrouwelijke vorm te kunnen schrijven.

De namen van de cliënten die in het boek gebruikt worden zijn uiteraard gefingeerd en waar we dachten dat het nodig was om meer zorg te besteden aan de privacy van de cliënt hebben we relevante persoonsgegevens veranderd.

Wanneer eenmaal een naam is gebruikt, blijft dezelfde cliënt deze naam houden in het boek. Dus Lieke of Mees komen op verschillende plaatsen in het boek op het toneel. Het kan dan om verschillende delen uit één sessie gaan of om verschillende sessies. Vaak verwijzen we daarbij naar de paragrafen waarin de bewuste cliënt eerder ter sprake is gekomen.

Tot slot willen we een woord van dank uitspreken. Aan alle opleiders en collega's die bijgedragen hebben aan onze vorming tot RET/CGT-therapeut. Aan alle ouders en kinderen met wie we de afgelopen jaren hebben mogen werken en van wie we veel hebben geleerd. We zijn speciale dank verschuldigd aan degenen die hun toestemming hebben gegeven om hun materiaal in audio-, beeld- of geschreven vorm te gebruiken voor nascholingstrajecten of voor dit boek.

Ten slotte noemen we in het bijzonder collega Hilda van der Steen, die de aanzienlijke moeite heeft genomen om alle laatste versies van de hoofdstukken te becommentariëren. De zorgvuldigheid waarmee ze dat gedaan heeft, getuigt van een grote betrokkenheid bij het vakgebied.

Gidia Jacobs

Nicole Muller

Esther ten Brink

Voorschoten, zomer 2001 